\title{
Long-Term Effects of ACE Inhibitors in Post-Tuberculosis Emphysema
}

Myung A Kim, M.D., Ph.D., Chang-Hoon Lee, M.D., Deog Kyeom Kim, M.D., Hee Soon Chung, M.D., Ph.D. Department of Internal Medicine, Seoul Metropolitan Boramae Medical Center, Seoul National University College of Medicine, Seoul, Korea

Background: Little is known about the long-term effects of angiotensin-converting enzyme (ACE) treatment on post-tuberculosis emphysema. This study evaluated the effects of ACE inhibition on cardiac function and gas exchange in patients with post-tuberculosis emphysema.

Methods: At baseline and at 6 months after initiation of ACE inhibition therapy, patients underwent pulmonary function testing, arterial blood gas analysis, and echocardiography, both at rest and post exercise. Cardiac output (CO) and right ventricular ejection fraction (RVEF) were measured at those time points as well.

Results: After ACE inhibition; resting and post-exercise RVEF (Mean \pm SEM, 61.5 $\pm 1.0,67.6 \pm 1.2 \%$, respectively) were higher than at baseline $(56.9 \pm 1.2,53.5 \pm 1.7 \%)$. Resting and post-exercise CO $(6.37 \pm 0.24,8.27 \pm 0.34 \mathrm{~L} / \mathrm{min})$ were higher than at baseline $(5.42 \pm 0.22,6.72 \pm 0.24 \mathrm{~L} / \mathrm{min})$. Resting and post-exercise $\mathrm{PaO}_{2}(83.8 \pm 1.6,74.0 \pm 1.2 \mathrm{mmHg}$, respectively) were also higher than at baseline $(74.2 \pm 1.9,66.6 \pm 1.6 \mathrm{mmHg})$. Post-exercise $\mathrm{PaCO}_{2}(46.3 \pm 1.1 \mathrm{mmHg})$ was higher than at baseline ( $44.9 \pm 1.1$; Resting $42.8 \pm 0.8$ vs. $42.4 \pm 0.9 \mathrm{mmHg}$ ). Resting and post-exercise A-a $\mathrm{O}_{2}$ gradient $(12.4 \pm 1.4,17.8 \pm 1.5 \mathrm{mmHg})$ were lower than at baseline $(22.5 \pm 1.5,26.9 \pm 1.6 \mathrm{mmHg})$.

Conclusion: In post-tuberculosis emphysema, RVEF and CO were augmented with a resultant increase in peripheral oxygen delivery after ACE inhibition. These findings suggest that an ACE inhibitor may have the potential to alleviate co-morbid cardiac conditions and benefit the patients with post-tuberculosis emphysema.

Key Words: Angiotensin-Converting Enzyme Inhibitors; Tuberculosis; Pulmonary Emphysema; Cardiac Output

\section{Introduction}

In our previous study ${ }^{1}$, patients with post-tuberculosis emphysema (PTE) were found to have a higher $\mathrm{PaCO}_{2}$ and a lower right ventricular ejection fraction (RVEF) than patients with pure pulmonary emphysema (PE) at rest, whereas their $\mathrm{FEV}_{1}$ and $\mathrm{FVC}$ results were similar. No significant difference was found in resting $\mathrm{PaO}_{2}$ and A-a $\mathrm{O}_{2}$ gradient between the PTE and PE patient groups. However, after exercise, A-a $\mathrm{O}_{2}$ gradient was signifi-

Address for correspondence: Hee Soon Chung, M.D., Ph.D. Division of Pulmonary and Critical Care Medicine, Department of Internal Medicine, Seoul Metropolitan Boramae Medical Center, Seoul National University College of Medicine, Sindaebang 2-dong, Dongjak-gu, Seoul 156-707, Korea Phone: 82-2-870-2211, Fax: 82-2-870-3863

E-mail: heechung@snu.ac.kr

Received: Aug. 18, 2010

Accepted: Oct. 6, 2010 cantly widened in PTE, which strongly suggests that V/Q mismatching increased with exercise due to a combination of changes in pulmonary arterial pressure and total pulmonary perfusion (cardiac output) with clear redistribution of the right ventricular output to poorly ventilated areas. In addition, RVEF diminished with exercise in the PTE group, which showed clear hypercapnia and more severe hypoxia after exercise than the PE group.

Angiotensin II may contribute to hypoxic pulmonary hypertension due to its vasoconstrictor and growth-stimulatory effects on vascular smooth muscle cells. Therefore, the use of angiotensin-converting enzyme (ACE) inhibitors might reduce hypoxic pulmonary hypertension by reducing pulmonary vasomotor tone and/or vascular remodeling ${ }^{2}$.

Recently, several studies have been reported that ACE inhibitors can reduce exacerbations and mortality, and 
treat cardiovascular co-morbid conditions in patients with $\mathrm{COPD}^{3-5}$. However, its long-term use in patients with PTE has not been studied.

We hypothesized that right ventricular function and V/Q matching are likely to be altered by long-term ACE inhibition in PTE, since ACE inhibition alters pulmonary arterial pressure and right ventricular afterload, which can be crudely estimated from mean pulmonary arterial pressure. The aim of this prospective study was to assess the effects of long-term ACE inhibition on the heart, and gas exchange both at rest and after exercise in patients with PTE.

\section{Materials and Methods}

\section{Patient population}

Based on medical history, clinical symptoms, and spirometric lung function and radiological findings, PTE patients were enrolled until 20 patients completed the study according to the protocol. All of the patients suffered from functional class II or III dyspnea (as classified by the New York Heart Association), had been in a stable state for 3 months before enrollment, and had not experienced respiratory failure or heart disease. The presence of significant emphysema was confirmed by HRCT; maximal transpulmonary pressure at TLC and cOefficient of retraction values were greater than $19 \mathrm{~cm}$ $\mathrm{H}_{2} \mathrm{O}$ and $2.5 \mathrm{~cm} \mathrm{H}_{2} \mathrm{O} / \mathrm{L}$, respectively, thus proving the presence of concomitant pneumosclerosis with emphysema in $\mathrm{PTE}^{6}$.

This study was approved by the Institutional Review Board of the hospital.

\section{Study protocol}

This study was designed to be minimally invasive, and neither right heart catheterization nor arterial cannulation was performed.

Pulmonary function testing, arterial blood gas analysis, symptom-limited exercise, and echocardiography were performed according to the following methods at baseline (before ACE inhibition) and then after 6 months of treatment with an ACE inhibitor, Ramipril (10 mg once/day).

No change in subject activity occurred during the study period, specifically, they did not participate in any rehabilitation or exercise program.

\section{1) Pulmonary function testing and arterial blood gas} analysis

Using a computerized flow-volume device and an automated body plethysmograph (CareFusion, San Diego, CA, USA), FVC, FEV $1, \mathrm{FEV}_{1} / \mathrm{FVC}, \mathrm{VC}, \mathrm{RV}, \mathrm{FRC}$, TLC and airway resistance were measured. Esophageal pressure was measured by inserting an intra-esophageal balloon, and lung compliance is defined as the slope of the pressure-volume curve between FRC and 0.5 L. Maximal transpulmonary pressure at TLC was measured using a body plethysmograph, and the coefficient of retraction (defined as the maximal pressure at TLC in $\mathrm{cm} \mathrm{H}_{2} \mathrm{O}$ divided by the volume at TLC in liters) was calculated ${ }^{6}$. DLco was measured using the single-breath method, as described by the American Thoracic Society standard ${ }^{7}$.

Arterial blood was withdrawn by radial puncture at rest and immediately after symptom-limited exercise (nearly simultaneously with the termination of exercise). Blood gases were analyzed using an automatic analyzer (GMI Inc., Ramsey, MN, USA), and A-a $\mathrm{O}_{2}$ gradient was calculated using the formula: $\left[\mathrm{A}-\mathrm{a} \mathrm{O}_{2}\right.$ gradient=150- $\mathrm{PaCO}_{2} / \mathrm{R}-\mathrm{PaO}_{2} \mathrm{~mm} \mathrm{Hg}$ w where R (respiratory quotient $)=0.8$ for room air.

\section{2) Symptom-limited exercise and echocardiography}

Exercise was performed by treadmill using a CASE8000 ergometer (GE Marquette Medical Systems, Munich, Germany) according to the Bruce (stepwise) proto$\mathrm{col}$, and was terminated when a patient complained of intolerable dyspnea. Maximal heart rate, blood pressure, exercise duration, and metabolic equivalents (METs) were recorded.

Echocardiography was done at rest and immediately after exercise using an Acuson Sequoier C-256 sonograph (Acuson Co., Malvern, PA, USA).

To evaluate right ventricular function, two-dimensional echocardiograms were recorded from apical and subcostal four-chamber views. The echocardiograms, recorded on videotapes, were analyzed in stop-frame 
mode. The area of the right ventricle was measured at end-diastole (the peak of the $\mathrm{R}$ wave by $\mathrm{EKG}$ ) and at end-systole (the end of $\mathrm{T}$ wave by EKG) during the expiratory cycle (since it was difficult for the dyspneic patients to hold breath after exercise). The final end-diastolic and end-systolic values were obtained by averaging 5 or 6 measurements. Right ventricular end-diastolic and end-systolic volumes were obtained from these values by using the modified biplane Simpson's method using the formula $\mathrm{V}=\pi / 4 \Sigma(\mathrm{I}=1-20)$ (two-chamber area) (four-chamber area) L/20, where $\mathrm{L}$ is the right ventricular long axis. RVEF, a measure of the systolic pump performance of the right heart, was calculated from these ventricular volumes.

LVEF and CO were measured from parasternal views, and pulsed, continuous and color-flow Doppler studies were also performed.

\section{Statistical analysis}

All analyses were performed using SPSS/PC program. Variables are expressed as mean \pm standard error of mean (SEM). Same patient's data were compared using the paired $t$-test, and $\mathrm{p}$-values of $<0.05$ are considered statistically significant.

\section{Results}

\section{Demography}

Twenty-four patients were enrolled in this study: 23 men and one woman, however, four participants dropped out, because of dizziness in one (only female) case, cough in another one case, and patient's request in the

\section{Table 1. Demographics of the study population}

\begin{tabular}{lc}
\hline \multicolumn{1}{c}{ Number } & 20 \\
\hline Age, yr & $57.9 \pm 2.1$ \\
Male/Female & $20 / 0$ \\
Height, cm & $169.2 \pm 3.6$ \\
Weight, kg & $59.8 \pm 2.7$ \\
Smoking, py & $23.4 \pm 4.5$ \\
Dyspnea grade & $2.3 \pm 0.2$ \\
\hline
\end{tabular}

Values are presented as mean \pm standard error of mean (SEM). py: pack year. other two cases.

The demographic characteristics of the patients who completed the study are displayed in Table 1.

\section{Pulmonary function and arterial blood gas profiles}

Pulmonary function profiles in PTE are summarized in Table 2. FVC was $65.0 \pm 4.2 \%$ (of predicted value), $\mathrm{FEV}_{1} 39.9 \pm 2.5 \%$, and the $\mathrm{FEV}_{1} / \mathrm{FVC}$ ratio $45.3 \pm 3.5 \%$. $\mathrm{RV}$ increased more than TLC did, and airway resistance was very high. Lung compliance did not increase, but $\mathrm{DL}_{\mathrm{CO}}$ reduced. After long-term ACE inhibition, no significant change was observed in the above variables.

At baseline; $\mathrm{pH}$ was $7.38 \pm 0.01$ at rest and $7.29 \pm 0.01$ after exercise. After exercise, $\mathrm{PaO}_{2}$ reduced from $74.2 \pm 1.9$ to $66.6 \pm 1.6 \mathrm{~mm} \mathrm{Hg}(\mathrm{p}<0.01)$ and $\mathrm{PaCO}_{2}$ increased from $42.4 \pm 0.9$ to $44.9 \pm 1.1 \mathrm{~mm} \mathrm{Hg}(\mathrm{p}<0.01$; Figure 1).

At 6 months after ACE inhibition, $\mathrm{pH}(7.39 \pm 0.01$ at rest and 7.27 \pm 0.18 after exercise) and resting $\mathrm{PaCO}_{2}$ ( $42.8 \pm 0.8 \mathrm{~mm} \mathrm{Hg} ; \mathrm{p}=0.524)$ were not altered. However, resting $\mathrm{PaO}_{2}(83.8 \pm 1.6 \mathrm{~mm} \mathrm{Hg})$ was higher than at

Table 2. Pulmonary function profiles in post-tuberculosis emphysema

\begin{tabular}{lcc}
\hline & $\begin{array}{c}\text { Measured } \\
\text { value }\end{array}$ & $\begin{array}{c}\text { \% of } \\
\text { predicted value }\end{array}$ \\
\hline FVC, L & $2.78 \pm 0.16$ & $65.0 \pm 4.2$ \\
$\mathrm{FEV}_{1}, \mathrm{~L} / \mathrm{sec}$ & $1.25 \pm 0.09$ & $39.9 \pm 2.5$ \\
$\mathrm{FEV} / \mathrm{FVC}, \%$ & $45.3 \pm 3.5$ & \\
$\mathrm{VC}, \mathrm{L}$ & $2.92 \pm 0.18$ & $68.8 \pm 4.8$ \\
$\mathrm{RV}, \mathrm{L}$ & $3.28 \pm 0.28$ & $151.1 \pm 11.4$ \\
$\mathrm{FRC}, \mathrm{L}$ & $4.33 \pm 0.29$ & $117.5 \pm 8.3$ \\
$\mathrm{TLC}, \mathrm{L}$ & $6.30 \pm 0.37$ & $103.7 \pm 6.0$ \\
$\mathrm{RV} / \mathrm{TLC}, \%$ & $51.5 \pm 2.3$ & \\
$\mathrm{R}_{\mathrm{AW}}, \mathrm{cm} \mathrm{H}_{2} \mathrm{O} / \mathrm{L} / \mathrm{sec}$ & $6.72 \pm 0.69$ & $386.2 \pm 73.8$ \\
$\mathrm{DL} \mathrm{co}, \%$ of reference & $79.8 \pm 4.4$ & \\
$\mathrm{Compliance}, \mathrm{L} / \mathrm{cm} \mathrm{H}_{2} \mathrm{O}$ & $0.096 \pm 0.011$ & \\
Maximal $\mathrm{P}_{\mathrm{TP}}$ at FRC, & $35.6 \pm 3.3$ & \\
$\mathrm{~mm} \mathrm{Hg}$ & & \\
$\mathrm{CR}, \mathrm{cm} \mathrm{H} \mathrm{H}_{2} \mathrm{O} / \mathrm{L}$ & $5.94 \pm 0.52$ & \\
\hline
\end{tabular}

Values are presented as mean \pm standard error of mean (SEM). FVC: forced vital capacity; FEV second; VC: vital capacity; RV: residual volume; FRC: functional residual capacity; TLC: total lung capacity; $\mathrm{R}_{\text {Aw: }}$ airway resistance; DLco: diffusing capacity for carbon monoxide; $\mathrm{P}_{\mathrm{TP}}$ : transpulmonary pressure; CR: coefficient of retraction. 

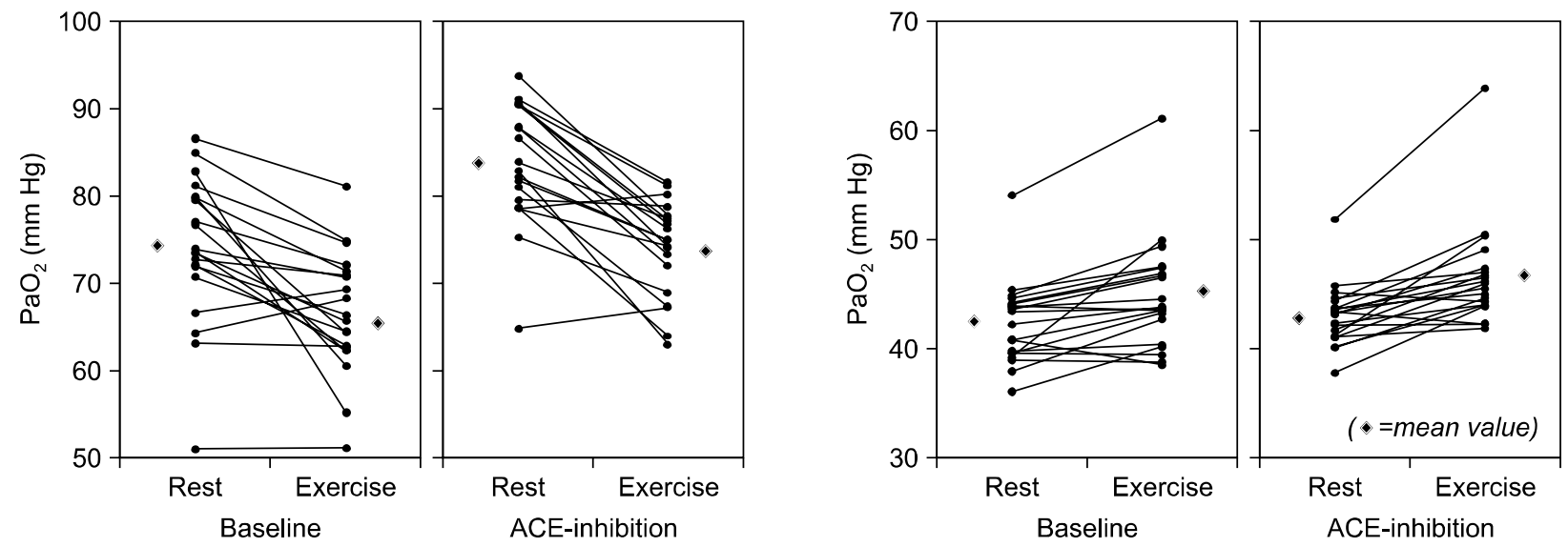

Figure 1. Changes in arterial blood gases after long-term ACE inhibition in post-tuberculosis emphysema. After ACE inhibition, resting and post-exercise $\mathrm{PaO}_{2}$ increased by ca. $10 \mathrm{~mm} \mathrm{Hg}$ (each $p<0.01$ ), whereas resting $\mathrm{PaCO}_{2}$ did not change $(p=0.524)$ and post-exercise $\mathrm{PaCO}_{2}$ increased by about $1 \mathrm{~mm} \mathrm{Hg}(p<0.01)$.
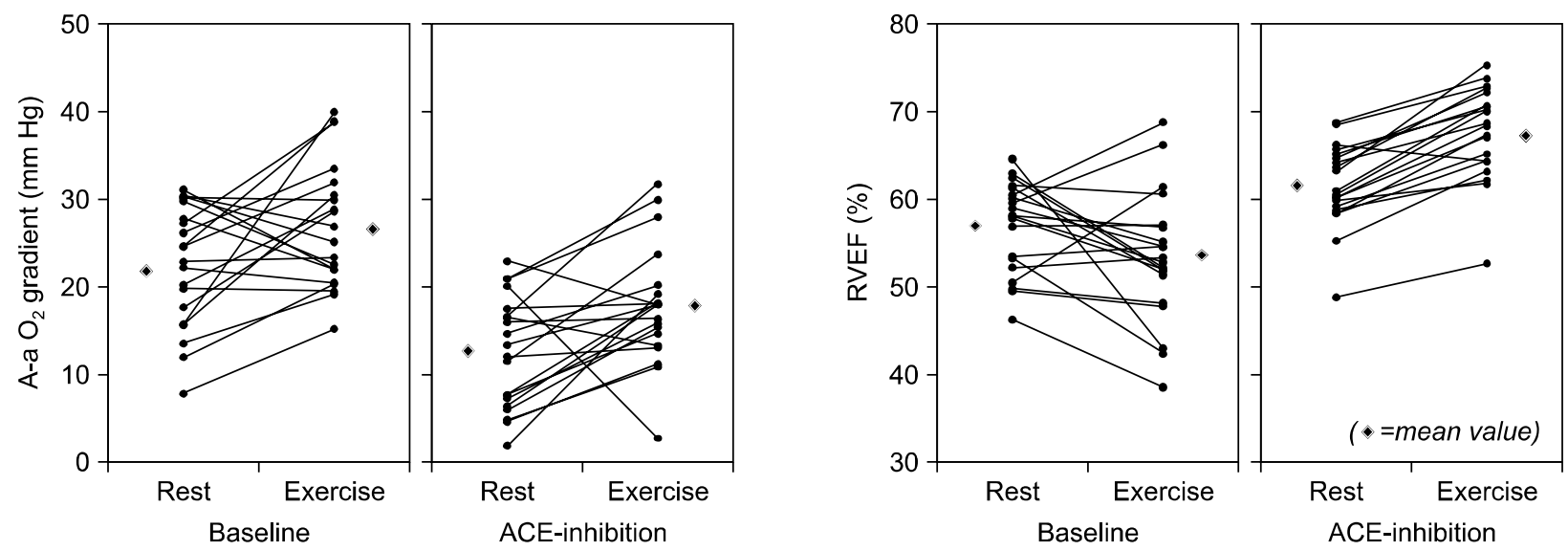

Figure 2. Changes in $\mathrm{A}-\mathrm{a} \mathrm{O}_{2}$ gradient and right ventricular ejection fraction (RVEF) after long-term ACE inhibition in post-tuberculosis emphysema. After ACE inhibition, resting and post-exercise $\mathrm{A}-\mathrm{a} \mathrm{O}_{2}$ gradient reduced by approximately $10 \mathrm{~mm} \mathrm{Hg}$ (each $p<0.01$ ). RVEF at rest was augmented by $5 \%$ after ACE inhibition and increased further with exercise-loading (each $p<0.01$ ), while RVEF at baseline was reduced by exercise-loading, without significance $(p=0.055)$.

baseline, and $\mathrm{PaO}_{2}$ reduced to $74.0 \pm 1.2 \mathrm{~mm} \mathrm{Hg}$ after exercise, but remained higher than that at baseline (each $\mathrm{p}<0.01)$. Post-exercise $\mathrm{PaCO}_{2}(46.3 \pm 1.1 \mathrm{~mm}$ $\mathrm{Hg}$ ) was higher than resting $\mathrm{PaCO}_{2}$ and than at baseline (each $\mathrm{p}<0.01$; Figure 1).

At baseline, $\mathrm{A}-\mathrm{a} \mathrm{O}_{2}$ gradient was $22.5 \pm 1.5 \mathrm{~mm} \mathrm{Hg}$ at rest and increased to $26.9 \pm 1.6 \mathrm{~mm} \mathrm{Hg}$ after exercise (p $<0.05)$. After ACE inhibition, resting $(12.4 \pm 1.4 \mathrm{~mm}$ $\mathrm{Hg})$ and post-exercise $(17.8 \pm 1.5 \mathrm{~mm} \mathrm{Hg}) \mathrm{A}-\mathrm{a} \mathrm{O}_{2}$ gradient were lower than at baseline (each $p<0.01$ ), but A-a $\mathrm{O}_{2}$ gradient increased after exercise $(\mathrm{p}<0.01$;
Figure 2).

\section{Exercise profiles and hemodynamic changes}

Exercise time was $344.9 \pm 31.7$ seconds at baseline and 357.5 \pm 39.2 seconds after ACE inhibition $(\mathrm{p}=0.387)$, whereas exercise performance was $7.41 \pm 0.59$ at baseline and 7.74 \pm 0.68 METs after ACE inhibition ( $\mathrm{p}=$ $0.453)$. Changes in hemodynamic profiles are summarized in Table 3. No clinically significant change was observed in systemic blood pressure or heart rate after ACE inhibition, although there were some statistically 
MA Kim et al: ACEl in post-TB emphysema

Table 3. Changes in Hemodynamic Profiles after ACE Inhibition

\begin{tabular}{|c|c|c|c|c|}
\hline & & Baseline & ACE inhibition & $p$-value \\
\hline \multirow[t]{3}{*}{ Resting } & systolic BP, mm Hg & $129.4 \pm 5.1$ & $123.8 \pm 4.8$ & 0.296 \\
\hline & diastolic BP, mm Hg & $88.1 \pm 3.4$ & $82.9 \pm 2.8$ & 0.052 \\
\hline & Heart rate & $96.6 \pm 4.1$ & $96.5 \pm 3.9$ & 0.981 \\
\hline \multirow[t]{3}{*}{ Post exercise } & systolic BP, mm Hg & $176.5 \pm 7.1$ & $163.5 \pm 9.3$ & $0.000^{*}$ \\
\hline & diastolic $\mathrm{BP}, \mathrm{mm} \mathrm{Hg}$ & $90.5 \pm 3.8$ & $95.6 \pm 5.7$ & 0.091 \\
\hline & Heart rate & $139.2 \pm 6.3$ & $143.2 \pm 5.2$ & $0.000^{\star}$ \\
\hline
\end{tabular}

Values are presented as mean \pm standard error of mean (SEM).

${ }^{*} p$-values $<0.05$ are considered statistically significant.

BP: blood pressure.
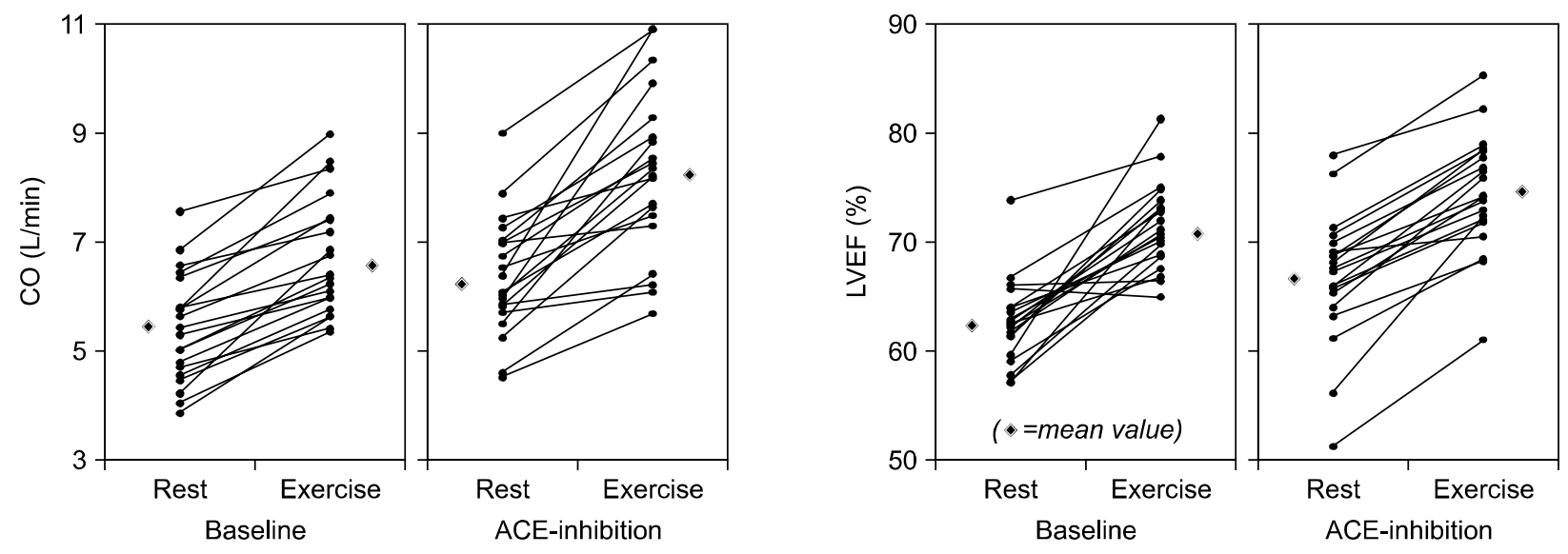

Figure 3. Changes in cardiac output (CO) and left ventricular ejection fraction (LVEF) after long-term ACE inhibition in post-tuberculosis emphysema. After ACE inhibition, resting and post-exercise CO increased by 1 to $1.5 \mathrm{~L} /$ min (approximately 20\%; each $p<0.01$ ), and LVEF increased by 3 to $4 \%$ both at rest and after exercise (each $p<0.05$ ).

significant differences. Pulmonary arterial pressure could not be assessed because of echocardiographic limitations.

At baseline, RVEF was $56.9 \pm 1.2 \%$ at rest and reduced to $53.5 \pm 1.7 \%$ after exercise, without significance $(\mathrm{p}=0.055)$. After ACE inhibition, resting RVEF (61.5 $\pm 1.0 \%)$ was higher than at baseline, and RVEF increased further to $67.6 \pm 1.2 \%$ after exercise (each $\mathrm{p}<$ $0.01)$, which was also higher than at baseline $(\mathrm{p}<0.01$; Figure 2).

At baseline, CO was $5.42 \pm 0.22 \mathrm{~L} / \mathrm{min}$ at rest and increased to $6.72 \pm 0.24 \mathrm{~L} / \mathrm{min}$ after exercise $(\mathrm{p}<0.01)$. After ACE inhibition, resting CO $(6.37 \pm 0.24 \mathrm{~L} / \mathrm{min})$ was higher than at baseline, and CO increased to $8.27 \pm 0.34$ $\mathrm{L} / \mathrm{min}$ after exercise $($ each $\mathrm{p}<0.01)$, which was also higher than at baseline $(\mathrm{p}<0.01$; Figure 3$)$.

At baseline, LVEF was $62.7 \pm 1.6 \%$ at rest and increased to $71.5 \pm 1.5 \%$ after exercise $(p<0.01)$. After ACE inhibition, resting LVEF $(66.7 \pm 2.7 \%)$ was higher than at baseline $(p<0.05)$, and LVEF increased to $74.5 \pm 2.6 \%$ after exercise $(p<0.01)$, which was also higher than at baseline $(\mathrm{p}<0.05$; Figure 3$)$.

\section{Discussion}

In patients with severe fibrotic pulmonary disease following tuberculosis, the clinical pattern of disease is almost indistinguishable from that of emphysema with severe airway obstruction ${ }^{8}$. Obstructive airway changes in PTE increase with age, the number of cigarettes smoked, 
and the extent of the initial tuberculous disease ${ }^{9,10}$. The impairment of pulmonary function found in this study was similar to that of stage III $\left(\mathrm{FEV}_{1} / \mathrm{FVC}<70 \% ; 30 \%\right.$ $\leq \mathrm{FEV}_{1}<50 \%$ predicted); Severe COPD according to the Global Initiative for Chronic Obstructive Lung Disease (GOLD) guidelines ${ }^{11}$.

In this study, considering decreased cardiopulmonary reservoir capacity in patients with PTE, symptom-limited exercise was adopted. However, post-exercise heart rates showed that exercise levels reached submaximal levels. Ideally, it is best to sample arterial blood during exercise to ensure steady conditions for gas analysis. However, instead, arterial blood gas analysis was done by direct arterial puncture immediately after exercise, because arterial cannulation was not performed. There was no measurable interval between sampling and exercise cessation.

Rubin suggested following guidelines for vasodilator therapy in cases of right ventricular failure or pulmonary hypertension $^{12}:$ 1) pulmonary vascular resistance is lowered by $20 \%, 2$ ) cardiac output is increased or unchanged, 3) pulmonary artery pressure is decreased or unchanged, and 4) systemic blood pressure is not significantly reduced (eg, no side effects). After these benefits are established and the patient has begun on a therapeutic regimen of a particular medication, right ventricular catheterization should be repeated after 4 to 6 months of continued therapy to ascertain whether the hemodynamic benefits persist. Adapting Rubin's guidelines, pulmonary function testing, arterial blood gas analysis, and echocardiography were repeated 6 months after ACE inhibition.

The normal response of the heart to exercise is at least a $5 \%$ increase in the ejection fraction of each ventricle $^{13}$. In this study, 17 of 20 patients (85.0\%) showed abnormal right ventricular response to exercise, and six patients $(30.0 \%)$ had abnormal left ventricular performance after exercise at baseline. These findings are consistent with the results of other studies, namely, that the prevalence of right ventricular dysfunction is high in patients with advanced pulmonary disease, but that the prevalence of left ventricular dysfunction is relatively low $^{13,14}$. After long-term ACE inhibition, abnormal rightor left-ventricular response to exercise was observed in only 2 cases $(10.0 \%)$, respectively.

The most common mechanism of reduced RVEF in advanced pulmonary disease is augmentation of right ventricular afterload ${ }^{13}$. RVEF may be depressed in the setting of pulmonary arterial hypertension, even if contractility is normal ${ }^{15}$. Although the cause of augmented afterload has not been established clearly, due to the potent pulmonary vasoconstrictor effect of hypoxemia, it appears to be a major factor leading to pulmonary hypertension. Pulmonary vascular destruction is an additional factor in these patients. Ultimately, chronic remodeling of the pulmonary vascular bed leads to reduced recruitability of pulmonary blood vessels ${ }^{15,16}$, and this restricted, relatively nonrecruitable pulmonary vascular bed with inordinate high pulmonary arterial pressure is considered to be the most likely mechanism of abnormal right ventricular response to exercise ${ }^{13}$.

Therapies with agents that reduce right ventricular afterload have the potential to improve the systolic performance of this chamber by reducing pulmonary vascular resistance and/or pulmonary arterial pressure ${ }^{12}$. Angiotensin II is a potent vasoconstrictor that induces the growth of vascular smooth muscle cells and increases collagen deposition, which leads to vascular remodeling $^{17}$, and it also plays a pivotal role in the remodeling of pulmonary arteries in hypoxia ${ }^{18}$. Therefore, ACE inhibitors have the potential to improve the pump performance of the right ventricle by reducing pulmonary vasomotor tone and/or vascular remodeling ${ }^{2}$.

ACE inhibitors may have other beneficial effects in COPD, as angiotensin II may have proinflammatory effects $^{19}$, and polymorphisms of the ACE gene have been linked to increased susceptibility to COPD $^{20}$. Because ACE inhibitors are routinely used in the management of hypertension, cardiac failure, and diabetes, all of which are common comorbidities of COPD, prospective trials of ACE inhibitors in patients with COPD are now warranted $^{21}$.

It was suggested that peripheral oxygen delivery and exercise oxygen consumption in patients with COPD are 
dependent on $\mathrm{CO}$, which, in turn, is related to the right ventricular function ${ }^{22}$. The most notable findings of this study were an increase in $\mathrm{PaO}_{2}$ and a decrease in A-a $\mathrm{O}_{2}$ gradient associated with an increase in ventricular ejection fraction, especially in RVEF after long-term ACE inhibition in PTE. These findings can be explained as follows: RVEF was depressed at baseline in PTE. After ACE inhibition, the systolic performance of right ventricle increased, as it was augmented by a reduced right ventricular afterload, and total pulmonary perfusion (CO) increased. For a given oxygen consumption, an increase in $\mathrm{CO}$ would increase mixed venous oxygen tension and increase $\mathrm{PaO}_{2}$, even if the distributions of V/Q were unchanged. Furthermore, the increment of pulmonary perfusion might be redistributed to relatively well ventilated areas, possibly by changes in vasomotor tone and alterations in vascular remodeling. Therefore, A-a $\mathrm{O}_{2}$ gradient decreased and $\mathrm{PaO}_{2}$ increased at rest after ACE inhibition. However, these parameters were re-aggravated after exercise due to respiratory pump insufficiency and the redistribution of right ventricular output to poorly ventilated, sclerosed portions of the lung in $\mathrm{PTE}^{1}$.

Right ventricular function has been shown to be important in such diseases as COPD, pulmonary thromboembolism, and right ventricular ischemia secondary to coronary artery disease ${ }^{13}$. Therefore, an ACE inhibitor can be used in these diseases if it favorably alters cardiovascular-pulmonary hemodynamics and right ventricular function. However, its routine use in stable COPD is not recommended11, because it may lower $\mathrm{PaO}_{2}$ by worsening V/Q matching, although it may acutely improve pulmonary hemodynamics ${ }^{22}$. Nevertheless, an ACE inhibitor might be also tried in selected cases of COPD, which show abnormal right ventricular response to exercise.

In PTE, the pump performance of the right heart and cardiac output were augmented after long-term ACE inhibition. V/Q mismatching was also alleviated (as evidenced by a reduction in A-a $\mathrm{O}_{2}$ gradient) with a resultant increase in peripheral oxygen delivery (as indicated by an increase in $\mathrm{PaO}_{2}$ ). These findings suggest that ACE inhibitor have the potential to alleviate co-morbid cardiac conditions and benefit the patients with PTE.

\section{References}

1. Kim MA, Kim SH, Zo JH, Hwangbo B, Lee JH, Chung HS. Right heart dysfunction in post-tuberculosis emphysema. Int J Tuberc Lung Dis 2004;8:1120-6.

2. Nong Z, Stassen JM, Moons L, Collen D, Janssens S. Inhibition of tissue angiotensin-converting enzyme with quinapril reduces hypoxic pulmonary hypertension and pulmonary vascular remodeling. Circulation 1996;94: 1941-7.

3. Mancini GB, Etminan M, Zhang B, Levesque LE, FitzGerald JM, Brophy JM. Reduction of morbidity and mortality by statins, angiotensin-converting enzyme inhibitors, and angiotensin receptor blockers in patients with chronic obstructive pulmonary disease. J Am Coll Cardiol 2006; $47: 2554-60$.

4. Cazzola M, Matera MG, Rogliani P, Page C. Treating systemic effects of COPD. Trends Pharmacol Sci 2007; 28:544-50.

5. Mortensen EM, Copeland LA, Pugh MJ, Restrepo MI, de Molina RM, Nakashima B, et al. Impact of statins and ACE inhibitors on mortality after COPD exacerbations. Respir Res 2009;10:45.

6. Schlueter DP, Immekus J, Stead WW. Relationship between maximal inspiratory pressure and total lung capacity (coefficient of retraction) in normal subjects and in patients with emphysema, asthma, and diffuse pulmonary infiltration. Am Rev Respir Dis 1967;96:656-65.

7. Lung function testing: selection of reference values and interpretative strategies. American Thoracic Society. Am Rev Respir Dis 1991;144:1202-18.

8. Poppius H. Airway obstruction in pulmonary tuberculosis. Scand J Respir Dis Suppl 1968;65:165-9.

9. Birath G, Caro J, Malmberg R, Simonsson BG. Airways obstruction in pulmonary tuberculosis. Scand J Respir Dis $1966 ; 47: 27-36$.

10. Snider GL, Doctor L, Demas TA, Shaw AR. Obstructive airway disease in patients with treated pulmonary tuberculosis. Am Rev Respir Dis 1971;103:625-40.

11. Global Initiative for Chronic Obstructive Lung Disease. Global strategy for the diagnosis, management, and prevention of chronic obstructive pulmonary disease. Washington: Medical Communications Resources; 2009.

12. Rubin LJ. Cardiovascular effects of vasodilator therapy for pulmonary arterial hypertension. Clin Chest Med 
1983;4:309-19.

13. Matthay RA, Arroliga AC, Wiedemann HP, Schulman DS, Mahler DA. Right ventricular function at rest and during exercise in chronic obstructive pulmonary disease. Chest 1992;101:255S-62S.

14. Vizza CD, Lynch JP, Ochoa LL, Richardson G, Trulock EP. Right and left ventricular dysfunction in patients with severe pulmonary disease. Chest 1998;113:576-83.

15. Schulman DS, Matthay RA. The right ventricle in pulmonary disease. Cardiol Clin 1992;10:111-35.

16. Matthay RA, Niederman MS, Wiedemann HP. Cardiovascular-pulmonary interaction in chronic obstructive pulmonary disease with special reference to the pathogenesis and management of cor pulmonale. Med Clin North Am 1990;74:571-618.

17. Willenheimer R, Rydberg E, Oberg L, Juul-Möller S, Erhardt L. ACE inhibition with ramipril improves left ventricular function at rest and post exercise in patients with stable ischaemic heart disease and preserved left ventricular systolic function. Eur Heart J 1999;20:1647-
56.

18. van Suylen RJ, Smits JF, Daemen MJ. Pulmonary artery remodeling differs in hypoxia- and monocrotaline-induced pulmonary hypertension. Am J Respir Crit Care Med 1998;157:1423-8.

19. Dandona P, Dhindsa S, Ghanim H, Chaudhuri A. Angiotensin II and inflammation: the effect of angiotensin-converting enzyme inhibition and angiotensin II receptor blockade. J Hum Hypertens 2007;21:20-7.

20. Busquets X, MacFarlane NG, Heine-Suñer D, Morlá M, Torres-Juan L, Iglesias A, et al. Angiotensin-converting-enzyme gene polymorphisms, smoking and chronic obstructive pulmonary disease. Int J Chron Obstruct Pulmon Dis 2007;2:329-34.

21. Barnes PJ. Future treatments for chronic obstructive pulmonary disease and its comorbidities. Proc Am Thorac Soc 2008;5:857-64.

22. Klinger JR, Hill NS. Right ventricular dysfunction in chronic obstructive pulmonary disease. Evaluation and management. Chest 1991;99:715-23. 